\title{
AN ASSESSMENT OF DIVERSITY AND SOCIO-ECONOMIC STATUS OF KALAMETIYA SANCTUARY
}

\author{
A J Y N Lakmali, D M S H K Ranasinghe and KP L Nishantha \\ Department of Forestry and Environmental Science, \\ University of Sri Jayawardhanapura,
}

Kalametiya Sanctuary is situated on the southeastern coast between Tangalle and Yala National Park. The area covered by Sanctuary including Kalametiya and Lunama lagoons is about 712 ha. The Kalametiya Sanctuary is very important for wildlife, particularly for birds. However, it has been largely destructed and the fishery resources of the lagoons are also reported to be depleted. The objectives of the study are to assess the floristic and faunistic diversity of some of the most prominent ecosystems within the Sanctuary and to assess the socio-economic status of the villagers in the neighbourhood. A management plan has also been prepared with a view to make conservation more efficient

Selective sampling was carried out in the 3 distinct ecosystems within the Sanctuary ie. mangroves, Arid Zone forest and the coastal ecosystem. Nine $10 \times 10 \mathrm{~m}$ plots were established in each ecosystem type. In these, the no. of species, no. of individuals in each species were assessed. DBH was measured in all the trees over $10 \mathrm{~cm} \mathrm{DBH}$. The saplings, bushes and small sized trees were recorded in plots of $5 \times 5 \mathrm{~m}$ within the large one. Small plots $1 \times 1 \mathrm{~m}$ were used to count the no. of ground flora (below $1 \mathrm{~m}$ height). Fauna in the respective ecosystems were also observed. In addition to these biological surveys, a questionnaire survey was conducted in five Grama Niladhari (GN) Divisions which are inside or at close proximity to the Sanctuary ie. Hunugama, Batata, South Hatagala, Lunama North and Lunama South. Ten families were selected from each GN Division which were selected randomly. Ecosystems were compared using floristic and faunistic composition and ecological indices. From the socio-economic survey the type and magnitude of pressures to the Sanctuary from the neighbouring communities were assessed.

In total, 72 plant species belonging to 34 families and 3301 individuals were counted in all the plots established in the Sanctuary in the Arid zone forest, mangrove forest and coastal vegetation ecosystem. The highest important values were shown by Cassia plnifrans, Sonnaratia caseolaris and Pandanus foetidus for the three ecosystems.

When taken separately, the density of three ecosystems were 105900,165300 and 59500 individuals/ha respectively for arid zone, mangrove forest and coastal vegetation. The highest diversity of 1.13 was shown by arid zone forest. Evenness of Arid zone forest and Coastal vegetation was same. The highest dominance was shown by Coastal vegetation. In the faunistic survey, 76 bird species were recorded. Questionnaire survey showed that the sampled villagers in and around the Kalametiya were having a low income, low education level and temporary occupations thus enabling adverse interaction with the sanctuary status of Kalametiya.

Preventing poaching, encroachments and shell mining and increasing the neighboring community can be recommended as probable measures to conserve the sanctuary successfully.

Proceedings of the Ninth Annual Forestry and Environment Symposium 2003 of the Department of Forestry and Environmental Science, University of Sri Jayewardenepura, Sri Lanka 